\title{
The influence of temperature on the fatigue behaviour of bituminous materials for pavement rehabilitation
}

\section{Fernando Moreno-Navarro*- $\mathbf{M}^{\mathrm{a}}$ Carmen Rubio- Gámez*_ Rodrigo Miró**__ Félix Pérez-Jiménez**}

* Laboratory of Construction Engineering of the University of Granada (LabIC.UGR) (Severo Ochoa s/n 18071, Granada, Spain)

fmoreno@ugr.es (correspondingauthor); mcrubio@ugr.es

** Technical University of Catalonia (Jordi Girona 1-3, Módulo B1, 08034 Barcelona, Spain)

r.miro@upc.edu; edmundo.perez@upc.edu

\begin{abstract}
.
The rehabilitation of deteriorated pavements has become one of the main concerns in road engineering. Thus, the development of more resistant bituminous mixtures to be used as surface layers is a priority for the sector. Discontinuous bituminous mixtures manufactured with modified binders at high dosages have been used with satisfactory results. Nevertheless, these materials are susceptible to temperature, and their performance is dependent on the climatic conditions. In order to improve the design of these mixtures, this research has focused on a better understanding of their fatigue behaviour as a function of temperature. This study has been conducted at both binder and mixture level using the EBADE and UGR-FACT tests, and it involves the analysis of various types of bituminous materials. The results showed that the temperature could play an important role in the success of this type of solution for the rehabilitation of deteriorated roads. It is therefore of interest to take this parameter into account for the effective design of bituminous mixtures.
\end{abstract}

KEYWORDS: asphalt pavement, bituminous mixtures, binder, EBADE, UGR-FACT,

temperature

EATA 2015, pages 1 to 18 


\section{Introduction}

In spite of the fact that most developed countries have almost completed their road and highway networks, in recent years their maintenance has emerged as an important issue for the pavement engineering sector. In particular, the profitability of the investments made on these infrastructures is directly related to the success of the rehabilitation program, both in terms of sustaining an adequate level of service, as well as avoiding the collapse of the structure. Thus, the development of resistant bituminous layers to be placed over the deteriorated road (which could help to extend its service life), has become a new priority for pavement technologists.

These types of bituminous mixtures need to meet the following requirements: (a) they should be placed in very thin layers $(2-4 \mathrm{~cm})$ because they are not conceived as a structural reinforcement; (b) they should have the bearing capacity to support traffic loads without flow; (c) and they should be flexible enough to resist fatigue phenomena and to dissipate the stresses transmitted from the bottom layers (produced by reflected cracks). Accordingly, recent years have seen the use of gap graded bituminous mixtures (such as SMA (EN 13108-5) or BBTM (EN 13108-2)) manufactured with high dosages of modified binders, an approach that has been met with some success (Costa et al., 2014). The appearance of plastic deformations in these types of mixtures is not very common, due to the reduced thickness of the layer, the resistance of their mineral skeleton (coarse aggregates are in direct contact), and the use of modified binder. The most critical factor, therefore, in determining he efficacy of these rehabilitation solutions is their fatigue cracking resistance to the reflective phenomena from the lower damaged layers.

Several studies have assessed the mechanical performance of these bituminous materials against fatigue and cracking (Wong \& Suo 2009; Moghadas et al., 2010; Hintz \& Bahia, 2013; Muniandy et al., 2014). As expected, due to the presence of high dosages of bitumen, their resistance is considerably higher than that offered by other types of bituminous mixtures. However, these high rates of binder render these materials very susceptible to temperature, and therefore the climatic conditions of the pavement play a very important role in their mechanical performance. It has thus been observed that rehabilitation layers that are suitable for some pavements might not be very effective in others (the defects of the bottom layers propagate quickly, appearing in the new surface).

Given that few studies have examined this issue, this research has focused on analysing the influence of the temperature on the fatigue phenomena and reflective cracking behaviour of surface layers commonly used in pavement rehabilitation. For this purpose, this study was conducted at both binder and mixture level. In particular, the rheological response of diverse modified and unmodified binders have been assessed using DSR frequency sweep tests at different temperatures. Based on these results, a range of temperatures of susceptibility was identified for the study of their 
fatigue resistance using the EBADE test (Pérez-Jimenez et al., 2012). Finally, having evaluated the long-term performance of the binders, we used the UGR-FACT method to examine, at various temperatures, the fatigue cracking resistance of various gap graded bituminous mixtures manufactured with these binders (Moreno-Navarro \& Rubio-Gámez 2013).

\section{Methodology}

\subsection{Materials}

Three asphalt binders were evaluated in this study: a conventional bitumen (B35/50), a SBS polymer modified bitumen (BM3c) and a crumb rubber modified bitumen (BC 50/70). These materials were selected in order to evaluate the differences in the temperature susceptibility of various binders commonly used in surface layers, along with their influence on the performance of the bituminous mixture. Table 1 summarizes the main characteristics of the binders.

Table 1. Properties of the binders studied

\begin{tabular}{lllll}
\hline $\begin{array}{c}\text { Bitumen } \\
\text { ID }\end{array}$ & $\begin{array}{c}\text { Penetration } \\
(\mathrm{dmm})\end{array}$ & $\begin{array}{c}\text { Softening } \\
\text { point }\left({ }^{\circ} \mathrm{C}\right)\end{array}$ & $\begin{array}{c}\text { Dyn. } \\
\text { Viscosity } \\
\text { @ 140 } \\
(\mathrm{mPa} . \mathrm{C})\end{array}$ & $\begin{array}{c}\text { Fraass } \\
\text { breaking } \\
\text { point } \\
\left({ }^{\circ} \mathrm{C}\right)\end{array}$ \\
\hline B 35/50 & 44 & 53.4 & 700 & -8 \\
BM3c & 62 & 68.4 & 1717 & -17 \\
BC 50/70 & 66 & 55.8 & 1083 & -14
\end{tabular}

Using these binders, three different gap graded bituminous mixtures (BBTM, EN 13108-2) were manufactured with the same mineral skeleton. This was composed of ophite in the coarse fraction, and limestone in the fine and filler fraction (Figure 1): BBTM-B35/50, BBTM-BM3c, BBTM-BC50/70. In order to provide a representative study of the influence of the binder properties on the mechanical performance of the mixtures, the same amount of bitumen was used in their production (avoiding the influence of this parameter). Thus, the only differences between the three mixtures were the type of binder used. Table 2 shows that the use of different binders does not exert a considerable influence in terms of strength (Marshall and Indirect Tensile), stiffness, density, or voids. 
4 EATA 2015

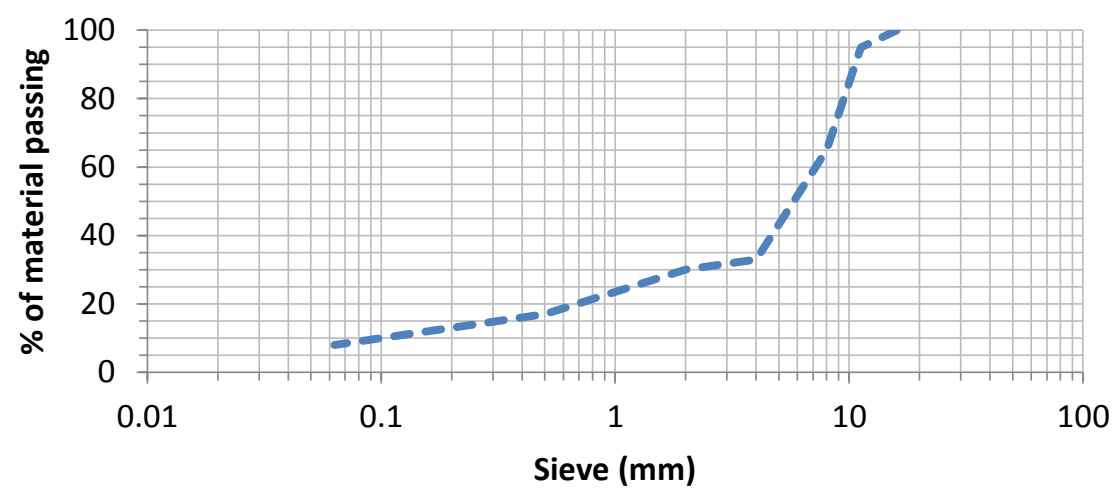

- Asphalt Mixture Mineral Skeleton

Figure 1. Grain size curve of the mineral skeleton used for the manufacture of the mixtures.

Table 2. Properties of the mixtures studied

\begin{tabular}{|c|c|c|c|c|c|c|}
\hline $\begin{array}{l}\text { Mixture } \\
\text { ID }\end{array}$ & $\begin{array}{c}\text { Binder } \\
\text { Content } \\
\text { (\% over } \\
\text { total } \\
\text { weight of } \\
\text { the } \\
\text { mixture) }\end{array}$ & $\begin{array}{c}\text { Bulk } \\
\text { density } \\
\left(\mathrm{g} / \mathrm{cm}^{3}\right)\end{array}$ & $\begin{array}{c}\text { Air } \\
\text { voids } \\
(\%)\end{array}$ & $\begin{array}{c}\text { Marshall } \\
\text { Stability } \\
(\mathrm{kN})\end{array}$ & $\begin{array}{c}\text { Marshall } \\
\text { Flow } \\
(\mathrm{mm})\end{array}$ & $\begin{array}{c}\text { Stiffness } \\
\text { Modulus } \\
\text { at } 20{ }^{\circ} \mathrm{C} \\
(\mathrm{MPa})\end{array}$ \\
\hline $\begin{array}{l}\text { BBTM-B } \\
35 / 50\end{array}$ & 5 & 2.496 & 4.8 & 8.662 & 3.3 & 4784 \\
\hline $\begin{array}{l}\text { BBTM- } \\
\text { BM3c }\end{array}$ & 5 & 2.464 & 5.2 & 9.301 & 3.9 & 3168 \\
\hline $\begin{array}{c}\text { BВTM-BC } \\
50 / 70\end{array}$ & 5 & 2.469 & 5.1 & 8.473 & 3.1 & 4310 \\
\hline
\end{tabular}




\subsection{Test procedure}

To define the range of temperatures where the fatigue behaviour of the bituminous materials should be evaluated, the rheological response of the different binders was analysed using the frequency sweep test at different temperatures $(10,20,30,40,45$, 52, 58, 64, 70 and $80^{\circ} \mathrm{C}$ ). This test was carried out using the Dynamic Shear Rheometer (DSR), and it applies oscillatory shear loading at a constant amplitude $(0.1 \%$ strain) over a range of loading frequencies (from $0.1 \mathrm{~Hz}$ to $20 \mathrm{~Hz}$ ). During the tests, complex shear modulus $\left(\mathrm{G}^{*}\right)$ and phase angle $(\delta)$ are recorded at each frequency (EN 14770). The results are displayed in the Black diagrams, which show, for each binder, the relationship between the values of complex shear modulus and phase angle at different temperatures. In addition, the results obtained for a fixed frequency $(5 \mathrm{~Hz})$ at different temperatures are displayed, in order to analyse the influence of this parameter on the visco-elastic response of the mixture.

Having defined the range of temperatures at which the fatigue response should be analysed (based on the results of the frequency sweep tests), the resistance to repeated loads of these binders was assessed using the EBADE test, represented in Figure 2 (Botella et al., 2012). This test has been developed at the Road Research Laboratory of the Technical University of Catalonia, and it is a cyclic tension-compression test at controlled strain.

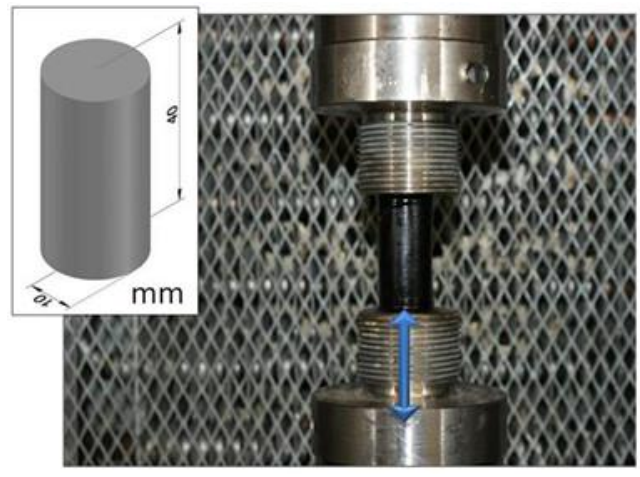

Figure 2. Image of the EBADE test used for bitumen specimens.

Several strain amplitudes are applied in ascending order, in units of 5,000 loading cycles, at a frequency of $10 \mathrm{~Hz}$. The strain amplitude applied in the first step is 7.6E4 , increasing by $7.6 \mathrm{E}-4$ at every 5,000 cycles. This ensures that the number of cycles and the strain amplitude are directly related.

Several parameters can be computed during the test. Using the maximum stress and strain, it is possible to obtain the complex modulus using the following equation [1]: 


$$
\mathrm{E}^{*}=\frac{\sigma_{\max }}{\varepsilon_{\max }}[1]
$$

Where $\mathrm{E}^{*}(\mathrm{MPa})$ is the complex modulus, $\sigma_{\max }(\mathrm{MPa})$ is the maximum stress amplitude registered in a cycle, and $\varepsilon_{\max }$ is strain amplitude imposed.

The initial modulus produced by the test is obtained from the average of the moduli registered in all cycles corresponding to the first strain step (amplitude of 7.6 E-4). At these low strain levels the behaviour of the material is linear.

Due to the delay between stress and strain, an ellipse is formed in the stress vs. strain plot. The density of dissipated energy is proportional to the area of the ellipse in the tension-compression graph. To compute this area from the test data, the Gauss Determinant Formula was used in the following equation [2]:

$$
\mathrm{DED}=\frac{1}{2}\left|\left(\sigma_{1} \varepsilon_{2}+\sigma_{2} \varepsilon_{3}+\cdots+\sigma_{\mathrm{n}-1} \varepsilon_{\mathrm{n}}+\sigma_{\mathrm{n}} \varepsilon_{1}\right)-\left(\sigma_{2} \varepsilon_{1}+\sigma_{3} \varepsilon_{2}+\cdots+\sigma_{\mathrm{n}} \varepsilon_{\mathrm{n}-1}+\sigma_{1} \varepsilon_{\mathrm{n}}\right)\right| \cdot 10^{6}[2]
$$

Where DED $\left(\mathrm{J} / \mathrm{m}^{3}\right)$ is Dissipated Energy Density, and $\sigma_{\mathrm{i}}(\mathrm{MPa})$ and $\varepsilon_{\mathrm{i}}$ are the $\mathrm{n}$ values of stress and strain obtained during a cycle.

These parameters are represented as a function of the number of cycles, which allows us to determine the development of both the modulus and the dissipated energy with the strain amplitude, since the number of cycles is related to the applied strain. Given the characteristics of the test, it is possible to obtain the strain at which the material is completely broken - the failure strain. In particular, the typical shape of the curves of dissipated energy density versus number of cycles permits us to determine the value of the failure strain. The reason for this is that DED increases throughout the test with the number of cycles, up to a maximum, after which it starts to decrease rather quickly as a result of the specimen failure. Consequently, a new parameter, termed failure strain, is defined as the strain at which the dissipated energy density is reduced by $50 \%$ of the maximum value reached during the test.

Finally, the fatigue cracking behaviour of the bituminous mixtures was evaluated using the UGR-FACT method (Moreno-Navarro \& Rubio-Gámez 2013). This test method was developed at the construction engineering laboratory of the University of Granada (LabIC.UGR) and it reproduces the conditions that lead to the appearance of fatigue cracking in pavements i.e., traffic loads and thermal gradients. The test device is composed of a base (Figure 3a), two supports where the specimen is fixed (Figure $3 \mathrm{~b}$ ), and a load application plate (Figure $3 \mathrm{c}$ ). The base has a platform that is composed of two sloping surfaces with two rails that allow for the sliding of the supports, and of two vertical spindles that are used to measure vertical deformations in the upper part of the test specimen (Figure 3d). The two supports are composed of a carriage that is adapted to the shape of the rail at the base (leading to effective load transmission), and a support plate (to which the test specimen is attached with epoxy resin) where the horizontal deformation gauges (LVDT) are located (Figure 3e). In addition, there are two elastic elements under these support plates that allow the flexion of the specimen 
(Figure 3f), and a spring that simulates the foundation layers (Figure 3g). The distance between the supports can vary, depending on the type of deterioration that needs to be reproduced (e.g., a crack, pre-crack, dilatation joint, pothole, etc.). Finally, the head of the load application is composed of a piece of steel that is thick enough to prevent deformations during the load application. This ensures the avoidance of differential errors that can arise due to its own deformation and which are unrelated to the test specimen, whilst providing a flat surface for the vertical deformation gauges (Figure 3f).
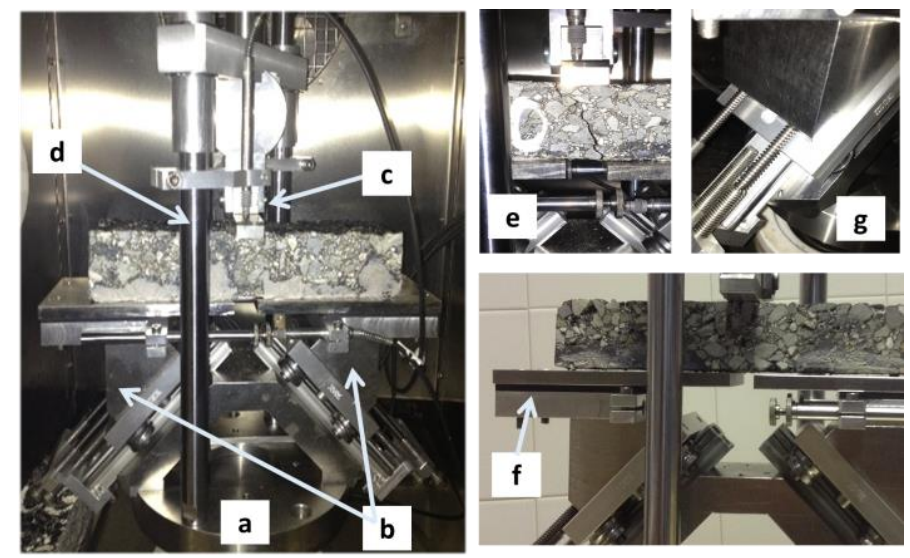

Figure 3. Description of the UGR-FACT test device (left: global view; right: details).

The simple geometry of the test device is capable of generating horizontal as well as vertical deformations in the test specimen, which reproduce the bending and shear stresses due to traffic loading, as well as the tensile strains induced by thermal gradients (Figure 4).
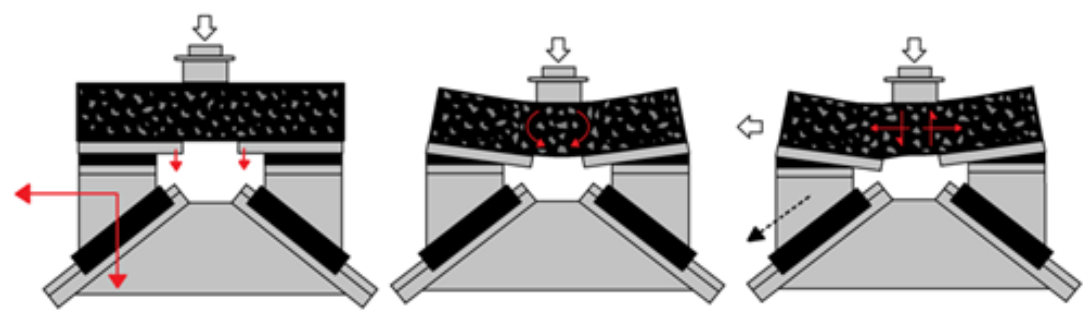

Figure 4. Sketch of the efforts induced using the UGR-FACT test device. 
For this purpose, a combined load function is used (Figure 5): a main up and down ramp that simulates thermal effects (with lower frequencies and higher amplitude) and a secondary verse-sine that represents traffic loads (with higher frequencies and lower amplitudes). In this case, (since the study focuses on the evaluation of susceptibility to temperature), the effect of the thermal gradients has been eliminated (the up and down ramp parameters remained at zero). Thus, the tests have been carried out with a unique verse-sine load of the same maximum amplitude at each cycle $(1.0 \mathrm{kN})$, and a frequency of $5 \mathrm{~Hz}$ at various test temperatures (defined as a result of the rheology tests).

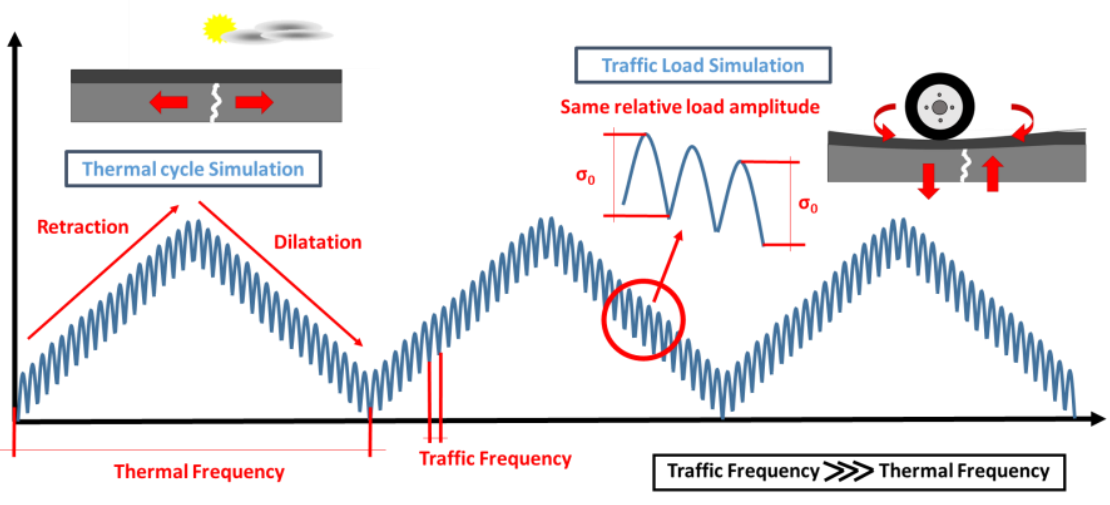

Figure 5. Outline of the loading function used in the UGR-FACT test.

The test method is therefore able to generate and propagate a controlled fatigue cracking process. The development of this process can then be examined through the energy that is dissipated in a representative volume of the specimen, avoiding randomness and tridimensional dispersion. The results are expressed in terms of dissipated energy, and the damage produced in the specimen is quantified in accord with the fact that only the difference in dissipated energy from one cycle to another causes degradation in the material (Shen et al. 2006; Shen \& Carpenter 2007). Thus, the cumulative RDEC (Ratio of Dissipated Energy Change, [3]) is used to analyse the evolution of damage in the specimen, and the Mean Damage Parameter $(\gamma,[4])$ is a value used to establish a reference for resistance to fatigue cracking in the pavement studied (Moreno-Navarro \& Rubio-Gámez 2014).

$$
R D E C_{n+1}=\frac{\omega_{n+1}-\omega_{n}}{\omega_{n}}[3]
$$

Where $\omega_{\mathrm{n}}$ is the energy dissipation produced in loading cycle $\mathrm{n}$ (in $\mathrm{J} / \mathrm{m} 3$ ), and $\omega_{\mathrm{n}+1}$ is the energy dissipation in loading cycle $\mathrm{n}+1$ (in $\mathrm{J} / \mathrm{m} 3$ ). 


$$
\gamma=\frac{\sum_{i=1}^{N_{f}} R D E C_{i}}{N_{f}}[4]
$$

Where $\mathrm{Nf}$ is the failure cycle of the specimen.

Table 3 summarizes the test procedure developed in this study.

Table 3. Test procedure developed in this study

\begin{tabular}{|c|c|c|c|}
\hline Test & Material tested & $\begin{array}{c}\text { Temperature } \\
\left({ }^{\circ} \mathrm{C}\right)\end{array}$ & $\begin{array}{c}\text { Number of specimens } \\
\text { tested (of each } \\
\text { material and } \\
\text { temperature) }\end{array}$ \\
\hline $\begin{array}{l}\text { Frequency } \\
\text { Sweep }\end{array}$ & $\begin{array}{c}\text { B35/50; } \\
\text { BM3c; } \\
\text { BC 50/70 }\end{array}$ & $\begin{array}{c}10,20,30,40 \\
45,52,58,64, \\
70, \text { and } 80\end{array}$ & 2 \\
\hline EBADE & $\begin{array}{l}\text { B35/50; } \\
\text { BM3c; } \\
\text { BC 50/70 }\end{array}$ & $-5,3$, and 10 & 3 \\
\hline $\begin{array}{l}\text { UGR- } \\
\text { FACT }\end{array}$ & $\begin{array}{l}\text { BВТМ- B35/50; } \\
\text { BВТМ-BM3c; } \\
\text { ВВТМ-BC50/70 }\end{array}$ & 5,15, and 25 & 3 \\
\hline
\end{tabular}

\section{Analysis of the results}

\subsection{DSR Frequency sweep tests}

Figure 6 shows the Black diagrams obtained from the frequency sweeps tests conducted on the different binders. It is clear that the two modified binders are thermorheologically complex (as highlighted by the non- superposition of the curves at high temperatures), due to the presence of the SBS and crumb rubber in the matrix of the binder. At low values of complex modulus (higher test temperatures), the modified binders present lower values of phase angle, meaning that there is a more elastic response of the materials, and thus more resistance to plastic deformations. However, at high values of complex modulus (lower test temperatures), the values of phase angle presented by the three binders are similar. This aspect of the results implies that the modified binders are showing a more stable visco-elastic response, which is due to the fact that they are less susceptible to temperature changes. 


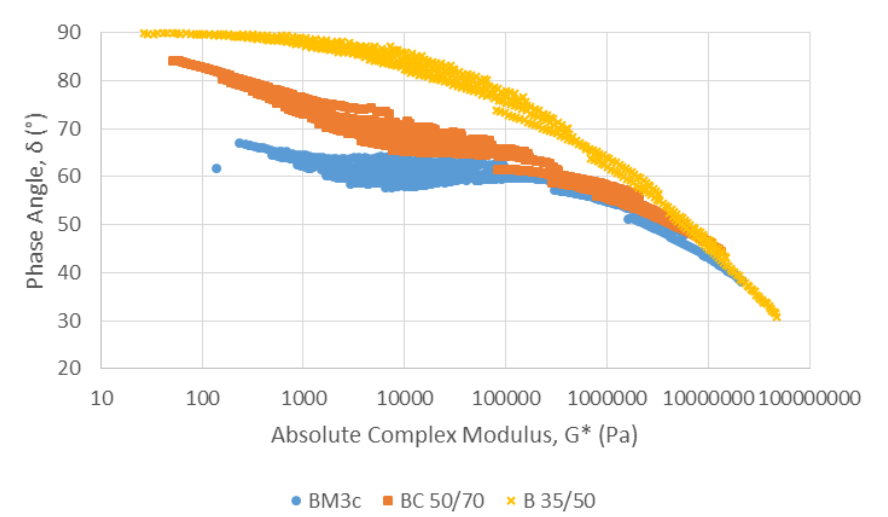

Figure 6. Black diagram curves obtained from the frequency tests.

This feature of the results can clearly be observed in Figure 7, which represents the values of phase angle for each test temperature at a fixed frequency of $5 \mathrm{~Hz}$. The slopes of the curves plotted for the modified binders (BM3c and BC50/70) are inferior to that displayed for the conventional binder (B 35/50). Nonetheless, a transition temperature can be observed where the three binders show similar rheological behaviour (from 15 to $30{ }^{\circ} \mathrm{C}$ ). Thus, within this range of temperatures, the benefits provided by the use of polymer modified binders could be reduced, and it could therefore be of interest to analyse the fatigue response of these asphalt materials under these circumstances.

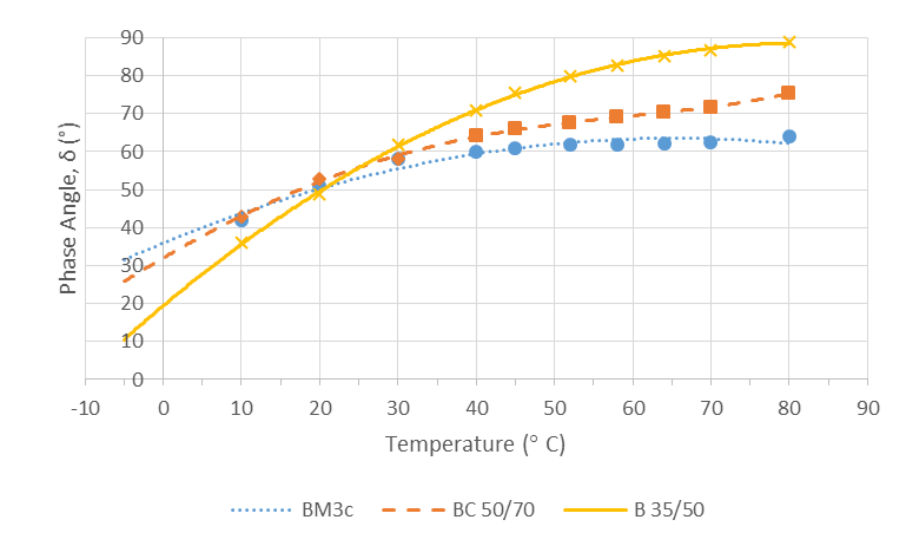

Figure 7. Representation of the phase angle as a function of temperature at $5 \mathrm{~Hz}$.

The fatigue response of the binders was assessed using the EBADE test, at three different temperatures: a considerably low temperature where the visco-elastic 
response of the binders (phase angle) is clearly different $\left(-5^{\circ} \mathrm{C}\right)$ and the benefits of using polymer modified binders should be clear; a temperature at which their viscoelastic responses become similar $\left(10^{\circ} \mathrm{C}\right)$, in order to assess possible differences that could be obscured when bituminous mixtures are evaluated; and an intermediate temperature to establish the correlation between the fatigue response of the binders and their rheological parameters $\left(3^{\circ} \mathrm{C}\right)$. Adopting the same criteria, the temperatures selected to carry out the UGR-FACT tests in the bituminous mixtures were: a low temperature outside of the transition range $\left(5^{\circ} \mathrm{C}\right)$; the initial temperature that defines the range $\left(15^{\circ} \mathrm{C}\right)$; and a temperature from within the range $\left(25^{\circ} \mathrm{C}\right)$. Using these test temperatures, we can observe the extent to which the fatigue cracking response of the bituminous materials is susceptible to the climate conditions of the pavement. It is therefore possible to assess the influence of temperature on the efficiency of overlay solutions.

\subsection{EBADE tests}

The EBADE tests were conducted on three specimens for each binder and test temperature, and the average curves representing the behaviour of the binder at the given test temperature were subsequently plotted. Figures 8 and 9 show these average curves for modulus and dissipated energy density, together with the imposed strain steps, for the BM3c binder at the three test temperatures. Two parameters that characterize the fatigue behaviour of the binder are obtained from this average result these are initial modulus and failure strain (Table 4).

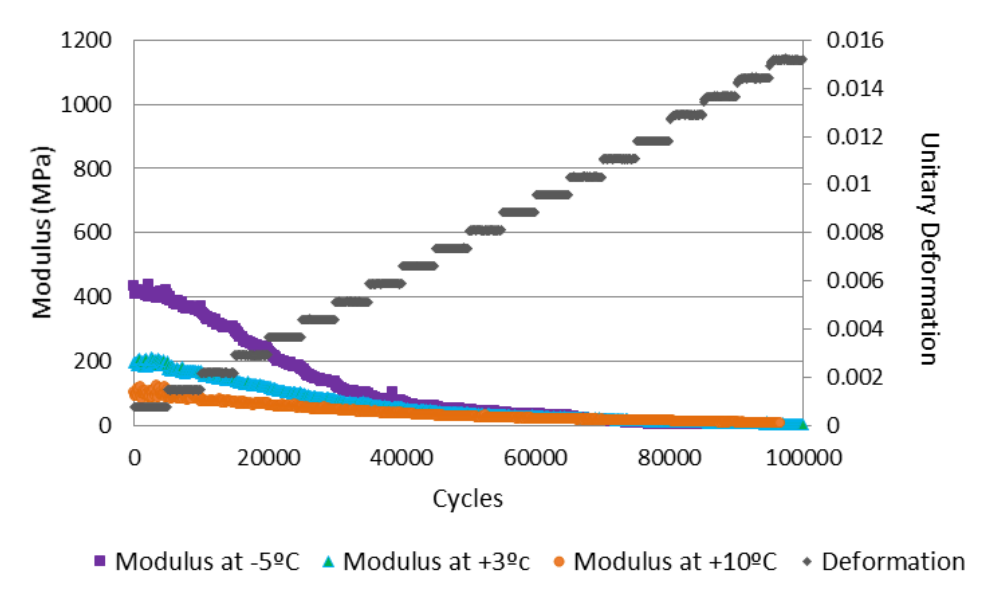

Figure 8. Evolution of the modulus for binder $\mathrm{BM} 3 \mathrm{C}$ at $-5,3$ and $10^{\circ} \mathrm{C}$. 


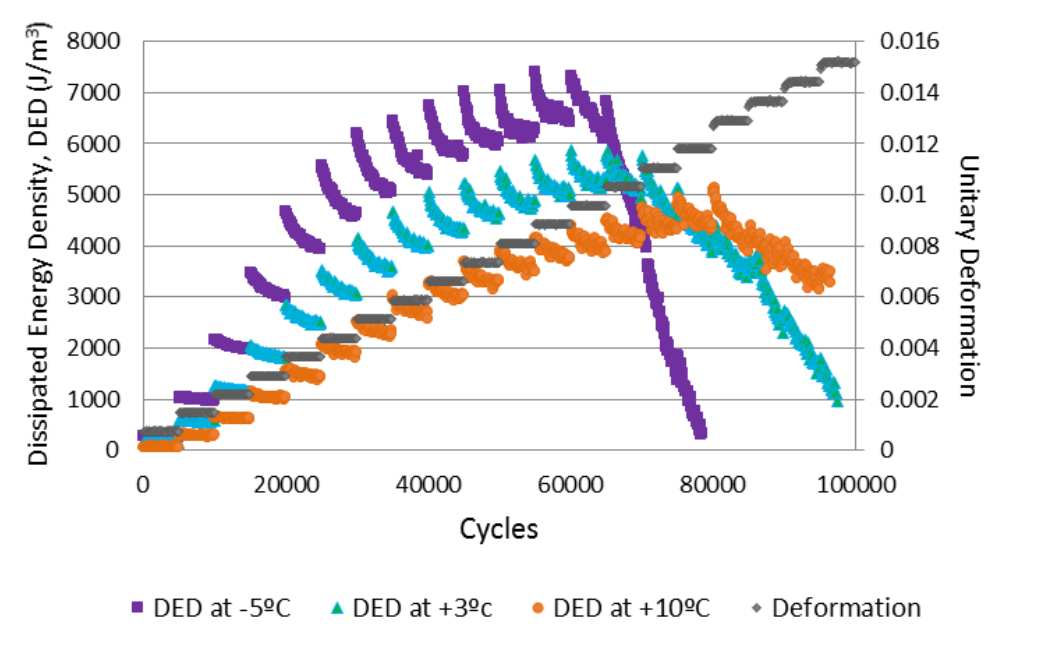

Figure 9. Density of dissipated energy for binder $B M 3 \mathrm{c}$ at $-5,3$, and $10^{\circ} \mathrm{C}$.

Table 4. Average values of initial modulus and failure strain for the tested binders

\begin{tabular}{lcll}
\hline Binder & Temperature $\left({ }^{\circ} \mathrm{C}\right)$ & $\begin{array}{c}\text { Initial } \\
\text { Modulus } \\
(\mathrm{MPa})\end{array}$ & Failure Strain \\
\hline \multirow{3}{*}{$\mathrm{B} 35 / 50$} & -5 & 868 & $2.18 \mathrm{E}-03$ \\
& 3 & 466 & $5.63 \mathrm{E}-03$ \\
$\mathrm{BC} 50 / 70$ & 10 & 238 & $6.61 \mathrm{E}-03$ \\
& -5 & 421 & $1.08 \mathrm{E}-02$ \\
$\mathrm{BM} 3 \mathrm{c}$ & 10 & 194 & $1.34 \mathrm{E}-02$ \\
& -5 & 86 & $1.52 \mathrm{E}-02$ \\
& 3 & 524 & $7.85 \mathrm{E}-03$ \\
& 10 & 224 & $9.59 \mathrm{E}-03$ \\
& 104 & $1.11 \mathrm{E}-02$
\end{tabular}

A comparison of the results of all the binders reveals that the polymer modified binder, $\mathrm{BM} 3 \mathrm{c}$, has the lowest initial modulus and the highest failure strain, whilst the crumb rubber modified binder shows similar behaviour, with a slightly higher modulus and lower failure strain. Finally, at all temperatures, the conventional binder has achieved both a higher (approximately 100\%) initial modulus, and much lower failure strain, when compared with the two modified binders.

Thus, there are two binders with high ductility, and one binder with considerably higher levels of stiffness. The data displayed in Figure 10, for instance, confirm this impression. This figure shows the variation in the density of dissipated energy as a function of the number of cycles in the EBADE test for the three binders at $-5^{\circ} \mathrm{C}$. 


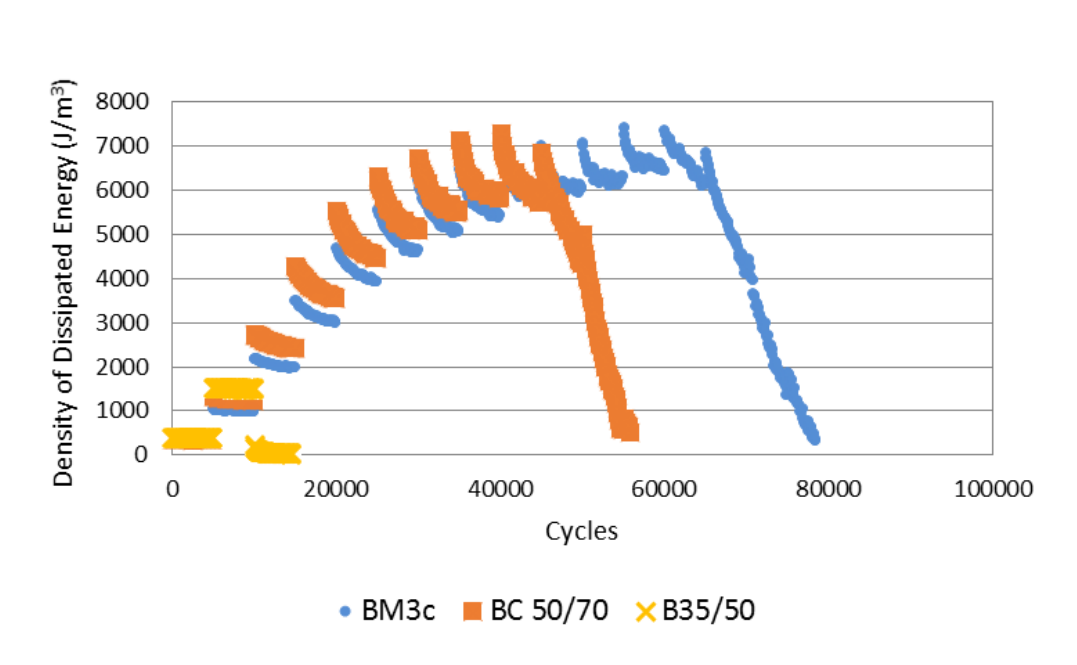

Figure 10. Evolution of the density of dissipated energy as a function of the number of cycles at $-5^{\circ} \mathrm{c}$ for the different binders tested.

Figure 10 shows how the BM3c binder and B35/50 binders display diametrically opposed behaviour. While BM3c is able to reach very high failure strains (1.08E-2), B35/50 fails at the third strain step (2.18E-2), this amplitude being almost 10 times lower.

Figure 11 displays, for all the binders, the values of failure strain versus initial modulus at all of the temperatures studied. This type of graph allows us to compare the fatigue behaviour of the different materials by simply observing the relative position of their curves. BM3c (blue) is on one end, with the lowest initial moduli and the highest failure strains; B35/50 is on the other end with the highest moduli and lowest failure strains, whilst the BC50/70 curve falls in between. In addition, it can be observed that as the test temperature decreases, the differences between the modified binders and the conventional one appears to be enhanced. This aspect of the results is compatible with those obtained in the DSR tests, and it shows the influence of the temperature on the long-term performance of the asphalt bitumen. 


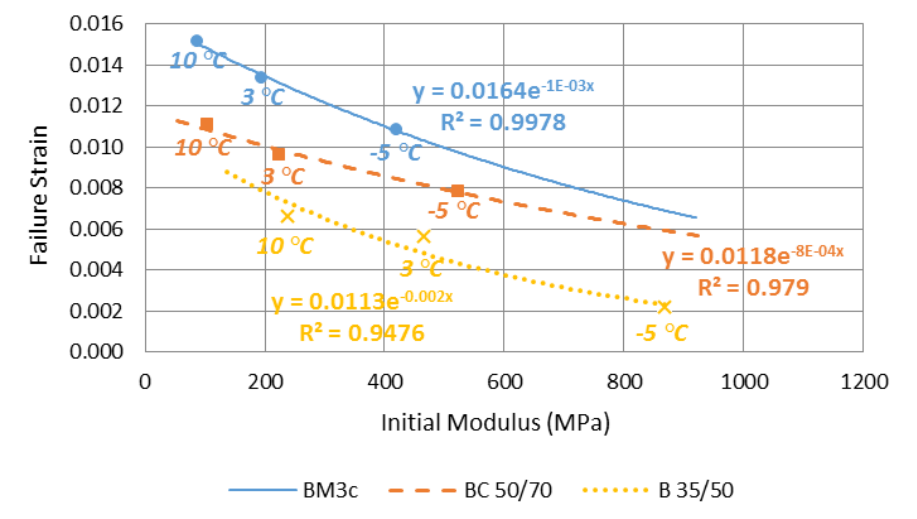

Figure 11. Failure strain versus initial modulus for the binders studied using the EBADE test (in the equations: $x=$ initial modulus; $y=$ failure strain).

\subsection{UGR-FACT tests}

Figure 12 shows the average amount of energy dissipated for the bituminous mixtures studied at the different temperatures. It is clear that, in all of the mixtures, an increase in the test temperature induces an increase in the amount of dissipated energy. This is because at high temperatures the asphalt materials behave in a more viscous manner, and thus the dissipated energy increases for a given stress level. For the same reason, as the number of load cycles increases, the amount of dissipated energy also increases (due to the appearance of damage in the material).

It is evident that at low temperatures $\left(5^{\circ} \mathrm{C}\right)$, where the rheological response of the binders is clearly different, the fatigue behaviour of the bituminous mixtures depends on the bitumen used. In particular, the bituminous mixture manufactured with the $\mathrm{BM} 3 \mathrm{c}$ resists a higher amount of load cycles than the mixtures manufactured with the $\mathrm{B} 50 / 70$ or the $\mathrm{B} 35 / 50$ (which is the mixture with a shorter fatigue life). Nevertheless, as the temperature increases $\left(15^{\circ} \mathrm{C}\right)$, the fatigue life of the mixtures becomes very similar (reducing the effect of the modified binders), and from $25{ }^{\circ} \mathrm{C}$ their mechanical response is inverted (the mixture manufactured with BM3c shows the shortest fatigue life). These results are in accord with those obtained from the binder tests (DSR and EBADE tests), which show the influence of the bitumen on the mechanical behaviour of asphalt mixtures, as well as the influence of the temperature of service on the performance of the bituminous materials. This pattern of results is also compatible with those found by other researchers who have carried out fatigue tests on binders and mixtures (Soenen et al., 2003). 

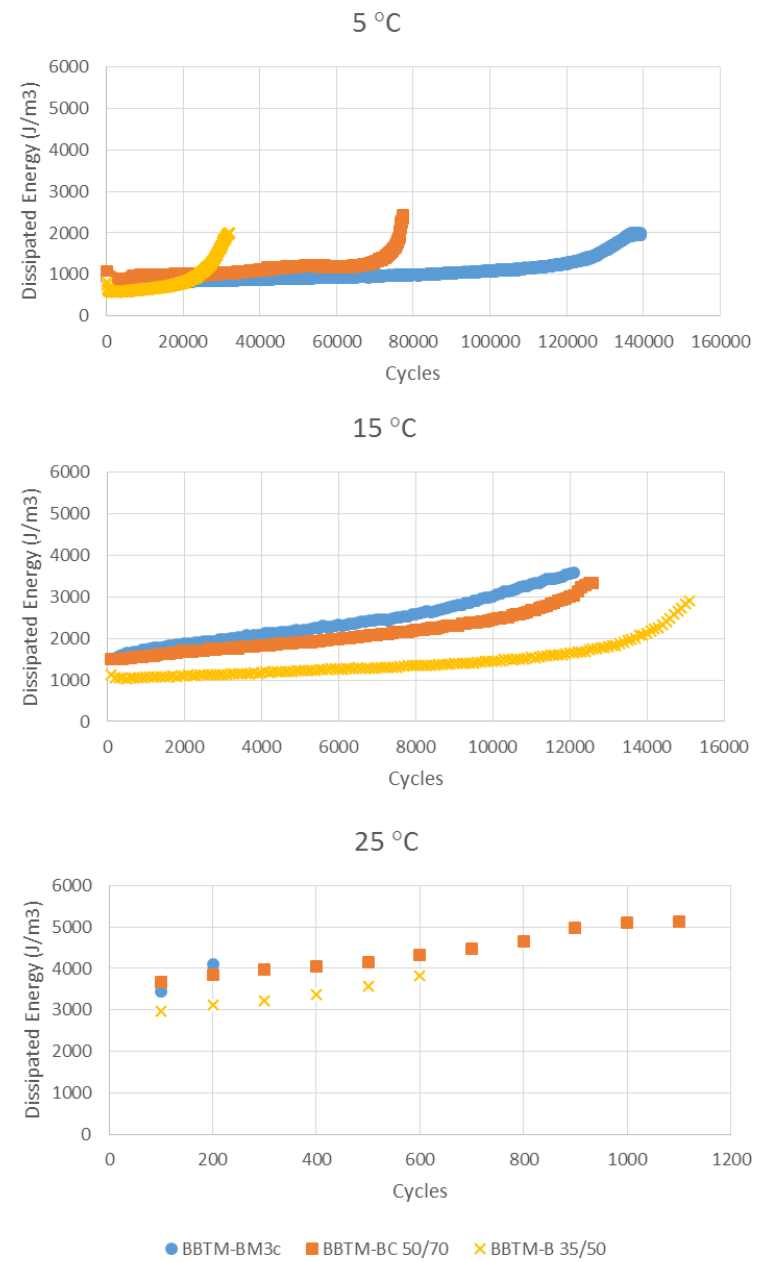

Figure 12. Average level of dissipated energy obtained for each material in the UGRFACT tests (it should be noted that the x-axes in the three plots are not uniform).

Figure 13 shows the average of the damage parameters obtained for the bituminous mixtures as a function of temperature (the error bars at each temperature are represented in terms of standard deviations). The results displayed in this figure are very similar to those in Figure 7. In mixtures manufactured using a binder with a lower phase angle (which behaves in a more rigid manner), the damage produced is higher than in mixtures manufactured with more flexible binders. Thus, at low temperatures the polymer modified binders reduce the damage caused by fatigue cracking, but when tested in the range of $15-30{ }^{\circ} \mathrm{C}$ (where the phase angle shows similar values) the mixtures behave in a much more similar manner. These results suggest the importance 
of the range of temperatures of the pavement, implying that if the road suffers from severe gradients of temperature, the use of modified bitumens in the rehabilitation overlays can exert a very positive effect on the service life of the solution. In contrast, if the service temperatures do not change considerably, it is more important to select an adequate binder (modified or not) that performs better within that temperature range.

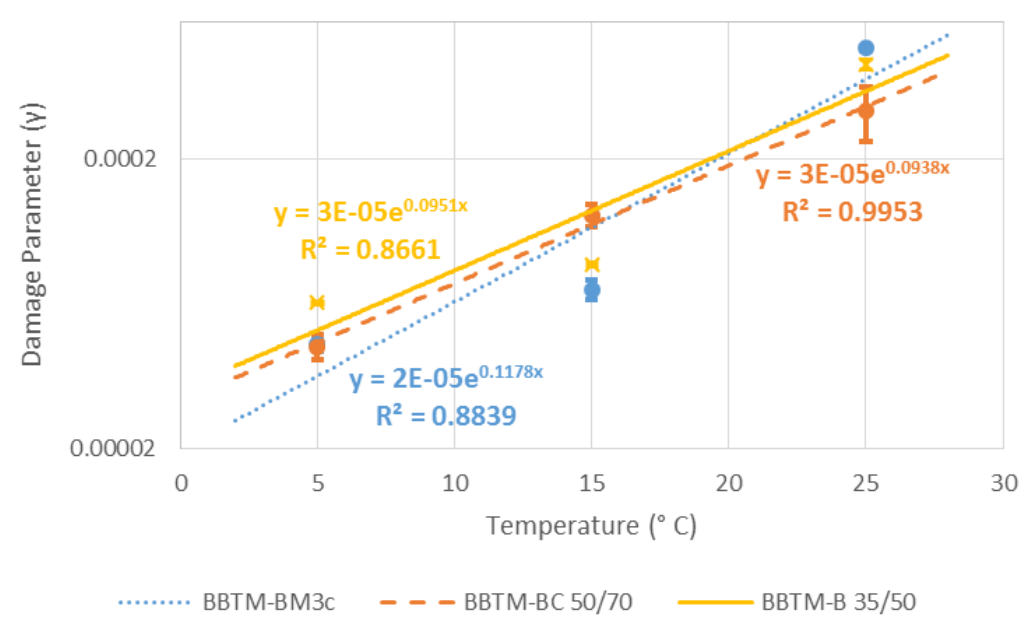

Figure 13. Damage parameters obtained for each bituminous mixture in the UGRFACT tests at different temperatures (in the equations: $x=$ temperature; $y=$ damage parameter).

\section{Conclusions}

The main distresses that induce the failure of rehabilitation surface layers in pavements are the reflective fatigue phenomena that are propagated from the deteriorated bottom layers (as they are used in thin layers, the appearance of plastic deformations is less likely). These surface layers are directly exposed to climatic conditions, and the ambient temperature could have a strong impact on their performance. Consequently, bituminous layers that are an effective rehabilitation solution for some pavements might not be as appropriate for others that face different climate conditions. This factor is not currently considered during the mixture design phase, and many rehabilitation layers have failed prematurely. This paper presents the results of a research study aimed at examining how temperature of service can have an impact on the fatigue behaviour of bituminous materials commonly used in pavement rehabilitation. For this purpose, several binder (DSR frequency sweep and EBADE) and mixture (UGR-FACT) tests were conducted at various temperatures. The main conclusions that can be derived from this study are summarized as follows: 
- The EBADE and UGR-FACT tests conducted in this study have shown that the rheological response of bituminous binders is directly related to the fatigue cracking resistance of asphalt mixtures. Thus, the long-term performance of asphalt mixtures will be highly influenced by changes in temperature.

- An important implication of these findings is that the temperature of service of the pavement will clearly affect the extent to which the bituminous materials can show resistance to fatigue phenomena. A given asphalt mixture could have a high resistance against this pathology at some temperatures, whilst showing low resistance at others. As a consequence, it will be very important to take into account the range of service temperatures during the design of these types of bituminous mixtures.

- In spite of the fact that modified binders exhibit a more stable rheological response as a function of temperature (displaying more viscous behaviour at low temperatures, and more elastic behaviour at high temperatures), there exists a certain range of temperatures where their performance is very similar to that displayed by conventional bitumens. This study has shown that if the fatigue resistance of asphalt materials is evaluated within this range of temperatures, it is difficult to find differences between modified and nonmodified binders. Nevertheless, as the test temperature varies from this range, the effect of the modifiers becomes more marked.

- Taken together, the findings of this study suggest that when designing a rehabilitation solution, it is of central importance to assess its fatigue cracking behaviour at temperatures similar to those that will affect it during its service life (and in some cases, this factor could be even more important than the type of binder selected).

\section{Acknowledgements}

The present article has been produced within the framework of a research project funded by the Agency of Public Works (AOPJA) of Andalusia (Spain), and co-funded by the FEDER funds.

\section{Bibliography}

Botella, R., Pérez Jiménez, F. \& Miró R. (2012). Application of a strain sweep test to assess fatigue behavior of asphalt binders. Construction and Building Materials, 36, 906-912. 
Costa, A., Loma, J., Hidalgo, M. E., Hergueta, J. A., Sánchez, F., Lanchas, S., ... Potti, J.J. (2014). Mezclas SMA (Stone Mastic Asphalt), sostenibles y medioambientalmente amigables. Comunicación 8, IX Jornada Nacional de ASEFMA, Madrid.

EN 13108-2 (2007): Bituminous mixtures. Material specifications - Part 2: Asphalt Concrete for very thin layers. AENOR, Asociación Española de Normalización y Certificación, Madrid.

EN 13108-5 (2007). Bituminous mixtures. Material specifications - Part 5: Stone Mastic Asphalt. AENOR, Asociación Española de Normalización y Certificación, Madrid.

EN 14770 (2012). Bitumen and bituminous binders. Determination of complex shear modulus and phase angle. Dynamic Shear Rheometer (DSR). AENOR, Asociación Española de Normalización y Certificación, Madrid.

Hintz, C. \& Bahia, H. (2013). Understanding mechanisms leading to asphalt binder fatigue in the dynamic shear rheometer. Road Materials and Pavement Design, vol. 14, sup 2, 231251.

Moghadas, F., Aflaki, N. E. \& Mohammadi, M.A. (2010). Fatigue behavior of SMA and HMA mixtures. Construction and Building Materials, 24, pp. 1158-1165.

Moreno-Navarro, F. \& Rubio-Gámez, M.C (2013). UGR-FACT test for the study of fatigue cracking in bituminous mixes. Construction and Building Materials, 43, pp. 184-190.

Moreno-Navarro, F. \& Rubio-Gámez, M.C. (2014). Mean damage parameter for the characterization of fatigue cracking behavior in bituminous mixes. Materials and design, 54: 748-754.

Muniandy, R., Akhir, N.A.B.C., Hassim, S., Moazami, D. (2014). Laboratory fatigue evaluation of modified and unmodified asphalt binders in Stone Mastic Asphalt mixtures using a newly developed crack meander technique. International Journal of Fatigue, vol. 59, pp. 1-8.

Pérez Jiménez, F., Botella, R. \& Miró, R. (2012). Differentiating between damage and thixotropy in asphalt binder's fatigue tests. Construction and Building Materials, 31, 212 219.

Shen, S. Airey, G., Carpenter, S. \& Huang H. (2006). A dissipated energy approach to fatigue evaluation. Road Materials and Pavement Design, vol. 7, issue 1, 47-69.

Shen. S. \& Carpenter, S. H. (2007). Dissipated energy concepts for HMA performance: fatigue and healing. Center of Excellence for Airport Technology, COE Report No. 29, Technical Report of Research, Federal Aviation Administration. University of Illinois at UrbanaChampaign, Urbana, IL.

Soenen, H., de La Roche, C. \& Redelius, P. (2003). Fatigue behaviour of bituminous materials: from binders to mixes. Road Materials and Pavement Design, vol. 4, issue 1, 7-27.

Wong, W. G. \& Suo, Z. (2009). Analysis of fatigue crack growth behavior in asphalt concrete material in wearing course. Construction and Building Materials, 23, 462-468. 